\title{
Exploring Ethical Development from Standard Instruction in the Contexts of Biomedical Engineering and Earth Science
}

\author{
Dr. Justin L Hess, Indiana University Purdue University, Indianapolis
}

Dr. Justin L Hess is the Assistant Director of the STEM Education Innovation and Research Institute and an Adjunct Assistant Professor of STEM Education Research in the Department of Technology Leadership and Communication at IUPUI. Dr. Hess's research interests include exploring empathy's functional role in engineering and design; designing STEM ethics curricula; and evaluating learning in the spaces of design, ethics, and sustainability. Previously, Justin worked as a Postdoctoral Researcher in the Weldon School of Biomedical Engineering at Purdue University where he created and refined ethical theory and learning modules to improve engineering students' ethical reasoning skills and dispositions. Justin received all of his degrees from Purdue University, inlacing his $\mathrm{PhD}$ in Engineering Education, Master of Science in Civil Engineering, and Bachelor of Science in Civil Engineering. Justin is the Program Chair-Elect of the ASEE LEES division and the vice chair of the American Society of Civil Engineers' Committee on Sustainability subcommittee on Formal Engineering Education.

\section{Mr. Grant A Fore, Indiana University Purdue University, Indianapolis}

Grant Fore is a Research Associate in the STEM Education Innovation and Research Institute (SEIRI) at Indiana University-Purdue University Indianapolis. As a SEIRI staff member, Grant is involved in research development, qualitative and mixed methods research, and programmatic assessment and evaluation. His research interests include ethics and equity in STEM education, the intersubjective experience of the instructor/student encounter, secondary STEM teacher professional development, and issues of power in STEM education discourse. He is also an Anthropology doctoral candidate at the University of Cape Town, where he was previously awarded a Master's degree. His dissertation research is focused on exploring the ethical becoming of architecture students within courses utilizing community-engaged pedagogies.

\section{Dr. Brandon H Sorge, Indiana University Purdue University, Indianapolis}

Brandon Sorge is an Assistant Professor of STEM Education Research in the Department of Technology Leadership and Communication at the Purdue School of Engineering and Technology at IUPUI. His research interests focus on creating a diverse and civically minded STEM citizenry. He is especially interested the impacts of all levels of policy, leadership, and corporate social responsibility on creating these outcomes. Before coming to IUPUI, Brandon ran the day-to-day operations of the Indiana STEM Resource Network where he co-founded the Indiana Science Initiative which provides research based science materials and professional development to approximately 2200 teachers impacting over 50,000 students each year.

\section{A Coleman, Indiana U Purdue U Indianapolis}

Martin A. Coleman is Associate Professor of Philosophy and Adjunct Associate Professor of American Studies at IUPUI in Indianapolis, Indiana. He is Editor and Director of the Santayana Edition, a critical edition of the works of American philosopher George Santayana. Coleman has published essays and edited volumes in American Philosophy.

\section{Dr. Mary F. Price}

ASEE Presentation Mary F. Price (price6@ iupui.edu ) is an anthropologist and Director of Faculty Development at the IUPUI Center for Service and Learning. Mary works with scholar-practitioners, students and community members to strengthen practice, deepen learning and facilitate the creation of actionable knowledge through intentional and equitable partnerships, grounded in the principles of democratic engagement. She has over 20 years experience working with high impact educational practices including: service-learning, study abroad, learning communities and faculty-mentored undergraduate research. She holds a masters in Latin American Studies from the University of Florida, Gainesville and a doctorate 
in anthropology from Binghamton University, SUNY. Some of her current scholarly interests include development strategies to support the retention and advancement of publicly engaged scholars, valuesengagement in assessment/research, and the role of relational expertise in community-academic partnerships.

Pronouns: she, her, her's

\section{Mr. Thomas William Hahn, IUPUI}

Thomas W. Hahn is the Director of Research and Program Evaluation at the Center for Service and Learning and Institute for Engaged Learning at Indiana University Purdue University Indianapolis (IUPUI). He is responsible for assessment, evaluation, and research in the areas of student civic learning, experiential learning, and success. Tom has over 20 years of experience in assessment and program improvement in higher education. He oversees the annual IUPUI Research Academy on Community Engagement and Engaged Learning and chairs the campus subcommittee for the student Experiential and Applied Learning Record. He received his undergraduate and graduate degrees from Old Dominion University in Norfolk, VA. 


\title{
Exploring Ethical Development from Standard Instruction in the Contexts of Biomedical Engineering and Earth Science
}

\begin{abstract}
Ethics continues to be required in the accreditation of engineers. However, ethics is seldom the core focus of departmental instruction. Yet, standard instruction may have myriad impacts on students' ethical development. This study explores students' ethical formation when ethics is a peripheral or non-intentional aspect of instruction in departmental courses in Biomedical Engineering and Earth Science. The research question that we seek to address is, "In what different ways and to what extent does participation in departmental engineering and science courses cultivate STEM students' ethical formation?" To address our research question, we disseminated a survey to students before (pre) and after (post) their participation in one of 12 courses offered in Earth Science or Biomedical Engineering during the Fall 2017 or Spring 2018. The survey included four instruments: (1) the Civic-Minded Graduate scale; (2) the Interpersonal Reactivity Index; (3) two relational constructs developed by the authors; and (4) the Defining Issues Test-2. Results suggest that current Earth Science curriculum, overall, positively contributes to students' ethical growth. However, the Biomedical Engineering courses showed no evidence of change. As the Earth Science courses do not explicitly focus on ethics, one potential explanation for this trend is the community-engaged nature of the Earth Science curriculum. These findings will be beneficial locally to help direct improvements in departmental STEM instruction. In addition, these findings pave the way for future comparative analyses exploring how variations in ethical instruction contribute to students' ethical and professional formation.
\end{abstract}

\section{Introduction}

The engineering curriculum is overcrowded. Hence, ethics is seldom the core focus of departmental instruction. Nonetheless, an emphasis on cultivating students' ethical reasoning skills and relational dispositions continues to be a core component of engineering accreditation [1]. Yet, the engineering curriculum in the United States has been found to decrease engineering students' concern for issues of public welfare [2]. Therefore, it seems that engineering curriculum needs radical redesign if engineering programs aspire to reverse this trend.

While, holistically, the engineering education curriculum seems to have a negative impact on students' social and public concerns, numerous individual interventions have proven effective at achieving myriad ethics-related learning goals [3-6]. However, as a cursory review of these articles will reveal, the specific learning objectives and associated strategies for integrating ethics into the engineering curriculum vary widely. As a result, there is not a single proven recipe for success in promoting engineering students' ethical formation, nor is there an agreed upon end.

In 2001, Haws [7] identified six prominent strategies utilized by engineering instructors for achieving ethics-related learning objectives. These included (1) professional codes of ethics, (2) humanist readings, (3) theoretical grounding, (4) ethical heuristics, (5) case studies, and (6) service learning. More recently, Hess and Fore [8] performed a systematic literature review and identified 16 distinct pedagogical strategies utilized in 26 articles. Often, instructors utilized multiple strategies concurrently, as Hess and Fore found that four instructional strategies were 
utilized in more than half of the selected literature. These included (1) codes or rules, (2) case studies, (3) discussion or debate, and (4) individual written assignments. Surprisingly (at least to us), community-engaged pedagogical strategies were discussed in only 2 of the 26 articles.

The range and disparity in instructional strategies may be partially due to discreet learning objectives. Hess and Fore identified three prominent categories of learning objectives. These included (1) ethical sensitivity or awareness, (2) ethical judgment, decision-making, or imagination, and (3) ethical courage, confidence, or commitment. Almost all articles synthesized by Hess and Fore focused on the first and second categories, but only 7 of the 26 articles sought to achieve learning goals associated with the third category.

We would like to draw a parallel with Orr [9] who argued, "All education is environmental education," meaning that, "By what is included or excluded, students are taught that they are part of or apart from the natural world" (p. 12). Likewise, we argue that all engineering education is ethics education. Students learn where ethics lives in engineering practice based on where (and how) ethics is explicitly included (or excluded) from the curriculum. Hence, all engineering curricula provide opportunities to explicitly focus on ethics. Inevitably, instructors are always influencing students' ethical development, albeit, oftentimes non-intentionally. Hence, even when analyzing a curriculum that does not explicitly focus on ethics (as we did in this study), students' professional formation is occurring. Whether ethical development is positive or negative varies, although as Cech [2] showed, too often the trends are in the negative direction.

\section{Study Overview}

This study explores students' ethical formation when ethics is a peripheral or non-intentional aspect of the instruction. More specifically, this study seeks to ascertain how standard departmental engineering and science curriculum influences students' ethical formation. The research question that we seek to address is, "In what different ways and to what extent does participation in departmental engineering and science courses cultivate STEM students' ethical formation?" We define ethical formation in terms of several skills and dispositions, including empathy [10], civic-mindedness [11], and ethical reasoning [12].

This study is part of a larger project that strives to explore the effectiveness of integrating community-engaged pedagogy and ethical reflection in the science and engineering curriculum [13]. During the 2018-2019 academic semesters, a subset of faculty from the courses surveyed in this study participated in a faculty learning community focused on ethics instruction and community-engaged pedagogy wherein they began redesigning courses by incorporating three components: (1) community-engaged pedagogy, (2) ethics, and (3) ethical reflection. As early as Fall 2019, faculty will begin implementing their redesigned courses. Hence, baseline data reported here will be compared with future modified curriculum to ascertain how the instructors' default mode of instruction compares with their modified curriculum. 


\section{Methods}

\section{Data Collection}

The primary data collected and analyzed in this study are survey data. We disseminated a survey to students before (pre) and after (post) their participation in one of 12 courses offered in Earth Science or Biomedical Engineering during the Fall 2017 or Spring 2018 semesters at a large Midwestern University. In addition to surveys, our team also conducted seven observations of five courses (three in Earth Sciences and two in Biomedical Engineering) to explore how (if at all) ethics and community-engaged pedagogy were situated within departmental courses, as well as where there is potential to expand upon their integration. Instructors of each course informed the research team as to when ethical content was likely to be covered in class. This strategy was intended to gather qualitative baseline data on classroom environments and instructional strategies to complement the quantitative survey data. In the discussion, we utilize these observations to further unpack and to help explain the quantitative findings.

The survey data represents faculty's current effectiveness at achieving various objectives of the project as measured by numerous constructs. In the results section, we report descriptive statistics for survey constructs before (pre) and after (post) students' participation in a departmental course. Importantly, these courses included minimal or no explicit ethics instruction. Hence, we did not expect changes to be significant.

The survey was administered online using Qualtrics survey software. Taken together, average completion time was approximately 25 minutes. For each self-report survey item, we utilized a nine-point Likert-type scale where the end-points were defined $(1=$ "Strongly Disagree" and $9=$ "Strongly Agree") and all items in-between represented a continuum from strong disagreement to strong agreement. We chose a nine-point Likert-type scale to increase the likelihood of identifying growth when utilizing constructs as part of an intervention (i.e., pre and post course). The following sub-sections describe each of the instruments and their associated constructs. Appendix A contains the complete survey with the exception of the DIT2 [14]

\section{Civic-Minded Graduate Scale (CMG)}

The Civic-Minded Graduate Scale [11] is a self-report instrument that includes four primary domains or constructs. In turn, each domain includes one to three sub-domains or sub-constructs. The domains and sub-domains include: (1) Knowledge - Volunteer Opportunities, Academic Knowledge and Technical Skills, and Contemporary Social Issues, (2) Skills - Listening, Diversity, and Consensus-Building Skills, (3) Dispositions- Valuing Community Engagement, Self-Efficacy, Social Trustee of Knowledge, and (4) Behavioral Intentions.

\section{Interpersonal Reactivity Index}

The Interpersonal Reactivity Index [15] is a self-report psychometric instrument that measures self-reported empathic tendencies via four subscales. In this study, we utilized only two subscales from the Interpersonal Reactivity Index: (1) Perspective-Taking and (2) Empathic Concern. Perspective-Taking represents one's tendency to consider the perspectives of another or 
others in general (i.e., non-engineering or science specific) everyday interactions. We describe perspective-taking as cognitive, meaning its focus is on mental processes and rational thought, as well as other-oriented, meaning it involves a focus on the mind of another [16]. In contrast, we describe empathic concern as affective, meaning its focus is primarily emotive [15]. We conceptualize empathic concern as other-oriented, but here there is also a focus on the self's internalized emotions resulting from a relation between self and other. Importantly, we slightly refined these constructs based on confirmatory factor analytic procedures [17].

\section{Interpersonal Self-Efficacy and Emotion Regulation}

In a prior study, we developed and validated two constructs: (1) Interpersonal Self-Efficacy and (2) Emotion Regulation [17]. We operationalized Interpersonal Self-Efficacy as the ability to successfully interact with others, including others who may have perspectives that diverge from one's own, and committing one's self to bearing in mind these external perspectives when finalizing a decision. This construct included four primary components: (1) Awareness of self; (2) Awareness of other; (3) Comfort with relation between self and other; (4) Commitment to diversity of thought. We operationalized Emotion Regulation as the ability to regulate emotions when faced with uncertainty and complexity while developing solutions or responses to a problem. This construct included four core components: (1) Awareness of self; (2) Comfort with complexity; (3) Acceptance of uncertainty; (4) Ability to cope with stress. Confirmatory factor analytic methods were utilized to clarify and validate the underlying factor structure of these constructs. In a prior study, we utilized confirmatory factor analytic procedures to establish each construct's structural validity, as well as to ascertain individual factor loadings or weights [17].

\section{Defining Issues Test 2 (DIT2)}

The Defining Issues Test or DIT2 [14] is a recognition task in which students prioritize responses offered in relation to a series of 5 ethical scenarios. In each dilemma, respondents rank 12 issues using a set of criteria indicating how important they perceive each issue is to the relevant case (response options included Great, Much, Some, Little, or No). The DIT2 results that we report in this study include: (1) The P score, which reflects an individual's capacity for post-conventional moral reasoning and (2) the N2 score, which measures an individual's affinity for post-conventional reasoning along with their rejection of pre-conventional or personal interest schema. The N2 score is measured by adjusting the P score based on "participants' ability to discriminate between [post-conventional] items and lower stage items [personal interest] items" [18]. These scores provide quantitative measures of the level of moral judgment of respondents. In this study, we report only the DIT2 N2 scores. The DIT2 data was collected by the auhors via Qualtrics and then shared with the Center for the Study of Ethical Development at the University of Alabama who computed and returned the DIT2 scores to the authors.

\section{Data Analysis}

First, we checked the internal reliability of all constructs by aggregating responses and calculating Cronbach's alpha. We utilized thresholds offered by DeVellis [19] where 0.80 or greater is excellent, 0.70-0.79 is acceptable, and 0.60-0.69 is minimally reliable. The lowest alpha was for pre-course responses to the Skills: Consensus Building subdomain $(\alpha=.66)$. 
Second, we computed individual CMG construct scores by taking the average of responses to all associated items. For the relational constructs, confirmatory factor analytic procedures were utilized [see 17 for a description of the CFA procedures]. Through CFA, we identified item loadings and these were utilized when computing construct scores. Specifically, the factor score was computed by multiplying individual responses to each item by the factor loading, summing these combined scores, and dividing by the cumulative factor loadings. In this way, scores for all constructs vary from a minimum of one to a maximum of nine, which is aligned with the same continuum as individual item responses (i.e., $1=$ Strongly Disagree, $9=$ Strongly Agree).

Third, we computed descriptive statistics pre- and post-course for each survey construct, including the mean (M) and standard deviation (SD). As we recognize that individual courses can have varied impacts on student growth, Appendix B summarizes student changes by course.

Fourth, we checked normality assumptions by computing the Shapiro-Wilks [20] coefficient for the difference scores for each construct. These analyses revealed that many difference scores were approximately non-normal.

Lastly, because difference scores tended to be non-normal, we conducted a series of Wilcoxon signed ranks tests [21] to ascertain if any pre/post changes were significant. This test involves calculating difference scores (i.e., post - pre) responses for each individual student, sorting these difference scores by magnitude, and assigning ranks a numerical value. Ties or difference scores of 0 are excluded from this ranking process. The remaining number of pairs is designated $N_{r}$. Ranks are assigned to all remaining difference scores wherein 1 represents the smallest magnitude of difference, 2 represents the second smallest magnitude of difference, and so on to $N_{r}$. Next, scores are separated into categories of positive difference scores and negative difference scores, and these separate piles are summed to generate a sum of ranks for both positive and negative difference scores. The test statistic, $W$, represents the sum of the signed ranks, with positive ranks contributing positively to this overall summation and negative ranks contributing negatively.

\section{Results}

\section{Participant Overview}

Instructors from several courses in the Earth Science or Biomedical Engineering curricula at IUPUI were contacted and asked for permission to disseminate a 25- to 30-minute survey to their students at the start and end of the Fall 2017 (nine courses) or Spring 2018 (three courses) academic semester. These courses were purposefully selected based on our objective of gathering a representative population of students across the departments.

In total, we received 246 complete pre (i.e., before course) responses and 158 complete post (i.e., after course) responses, or 155 complete pre/post responses. Fifty-six complete responses were received from students enrolled in at least one Biomedical Engineering course, and 99 complete responses were received from students enrolled in at least one Earth Science course. Response rates for individual courses varied from a low of $18.6 \%$ to a high of $77.3 \%$. 
Participants were primarily in the Schools of Engineering and Technology $(n=59)$ and Science $(n=57)$, although respondents were also from Liberal Arts $(n=8)$, Education $(n=10)$, and a few other disciplines $(n=7)$. Five respondents had not yet declared their major and academic major data were not available for two students. Fifty-three students were pursuing Biomedical Engineering Degrees whereas 49 students were pursuing Earth Science degrees, including 23 with an Environmental Science concentration (5 of whom were "pre" Environmental Science), 20 with a Geology Concentration (6 of whom were "pre" Geology), and 1 with an "Applied Earth Science" concentration (this student was pursuing a PhD).

The sample included 65 males and 83 females. Participants' racial backgrounds were primarily White $(\mathrm{n}=120)$. Participants varied widely in terms of academic standing, including 27 freshman, 31 sophomores, 44 juniors, 49 seniors, and 2 graduate students. Table 2 provides a summary of this information for the overall sample as well as by Biomedical Engineering and Earth Science enrollment. As of census Fall 2017, 109 students were enrolled in Environmental Sciences BS, Geology BA, Geology BS, or Geology BS/MS, and an additional 37 students were "pre" Earth Science. Hence, our sample represents approximately 34\% of the pre or current Earth Science majors at IUPUI. 203 students were enrolled in Biomedical Engineering indicating that our sample represents approximately $28 \%$ of this student population.

Table 1. Demographic Information of Participants

\begin{tabular}{|l|c|c|c|}
\hline \multicolumn{1}{|c|}{ Category } & Total & Majoring in Biomed. & Majoring in Earth Sci. \\
\hline Total & $\mathbf{1 4 8}^{*}$ & $\mathbf{5 3}$ & $\mathbf{4 9}$ \\
\hline Gender & & & 20 \\
\hline Male & 65 & 26 & 29 \\
\hline Female & 83 & 27 & 49 \\
\hline Race/Ethnicity & & & 1 \\
\hline White & 120 & 42 & 2 \\
\hline Asian & 6 & 3 & 1 \\
\hline Hispanic/Latino & 9 & 2 & 3 \\
\hline Black/African American & 5 & 0 & 0 \\
\hline Multi-Racial & 6 & 2 & 12 \\
\hline Nonresident Alien & 7 & 4 & 10 \\
\hline Academic Standing & & & 10 \\
\hline Freshman & 25 & 0 & 15 \\
\hline Sophomore & 29 & 6 & 2 \\
\hline Junior & 43 & 16 & 13 \\
\hline Senior & 47 & 31 & 9 \\
\hline Masters or PhD & 2 & 0 & 7 \\
\hline Pell Eligible & 37 & 12 & \\
\hline Transfer & 31 & & \\
\hline
\end{tabular}

* Seven students, each from Earth Science, completed surveys during the Fall and Spring semester. Data for these students is reported only once. These students are treated as distinct subjects in the subsequent sections unless explicitly noted. 


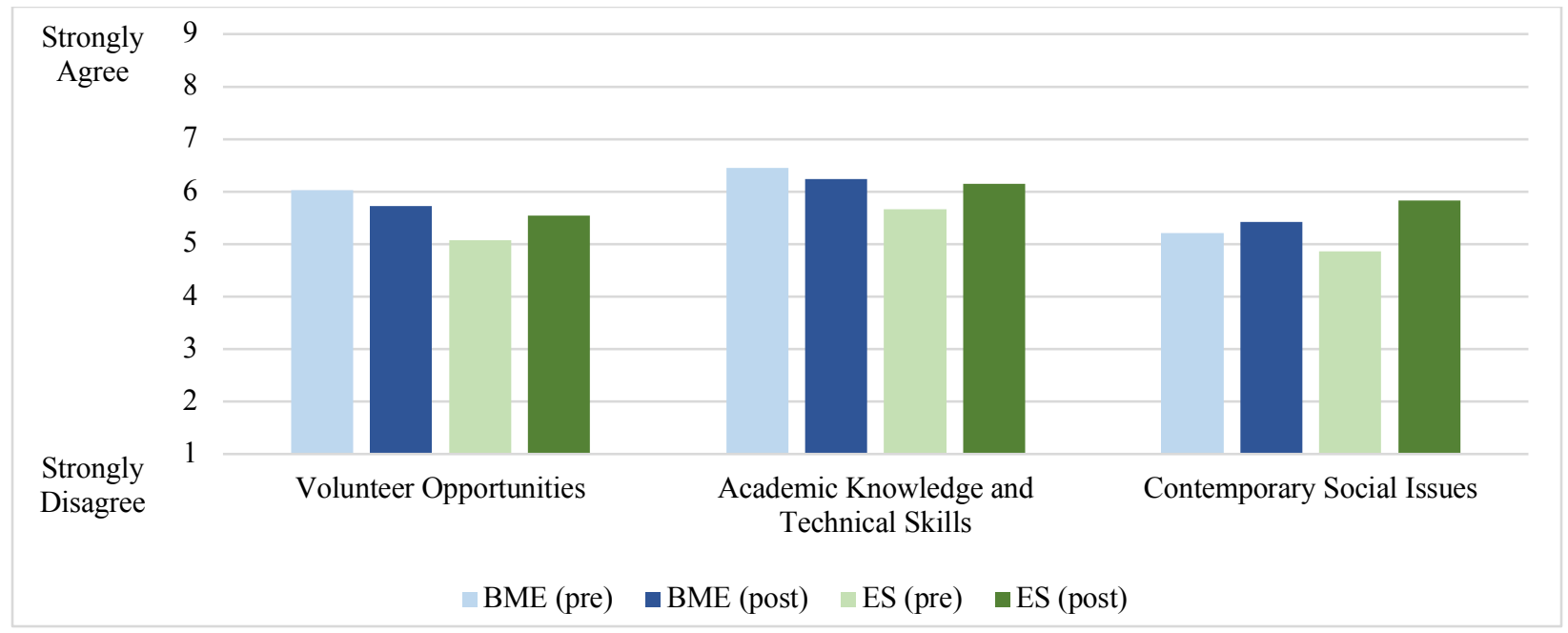

Figure 1. Pre/Post Responses to CMG Knowledge Sub-Domain

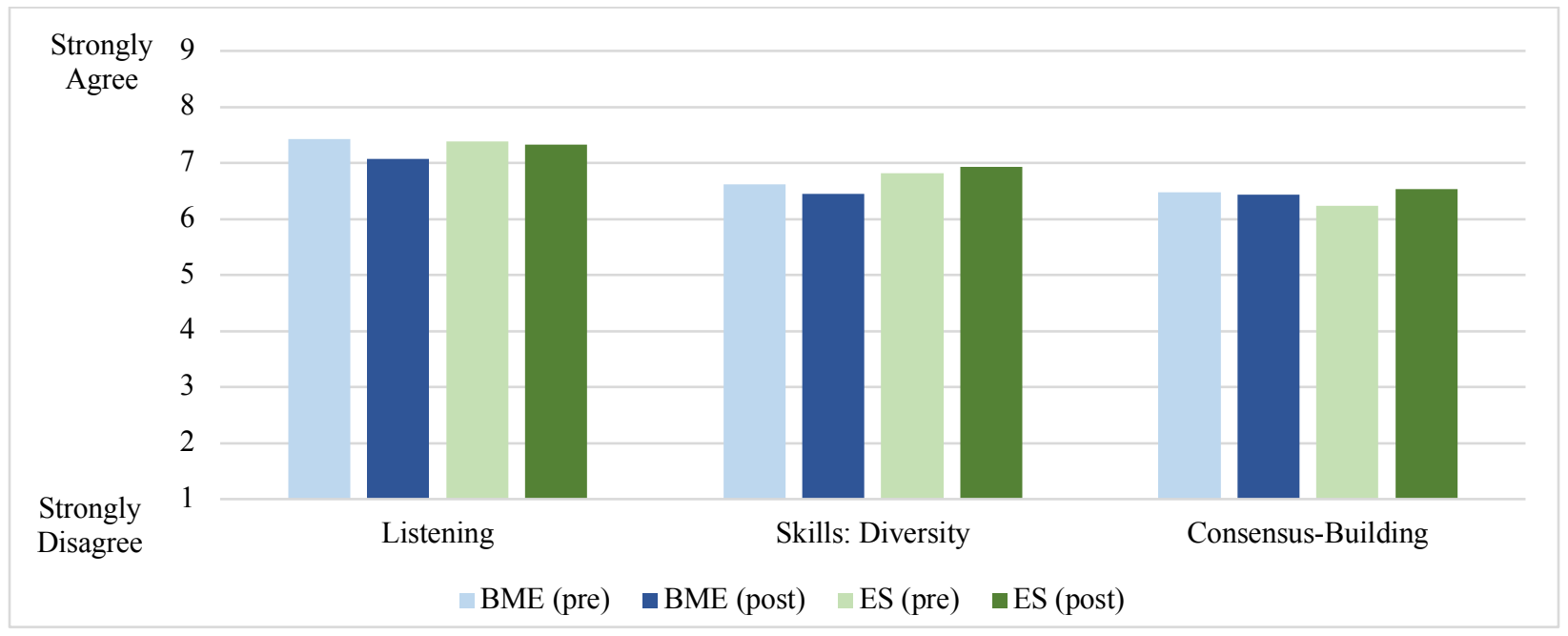

Figure 2. Pre/Post Responses to CMG Skills Sub-Domain

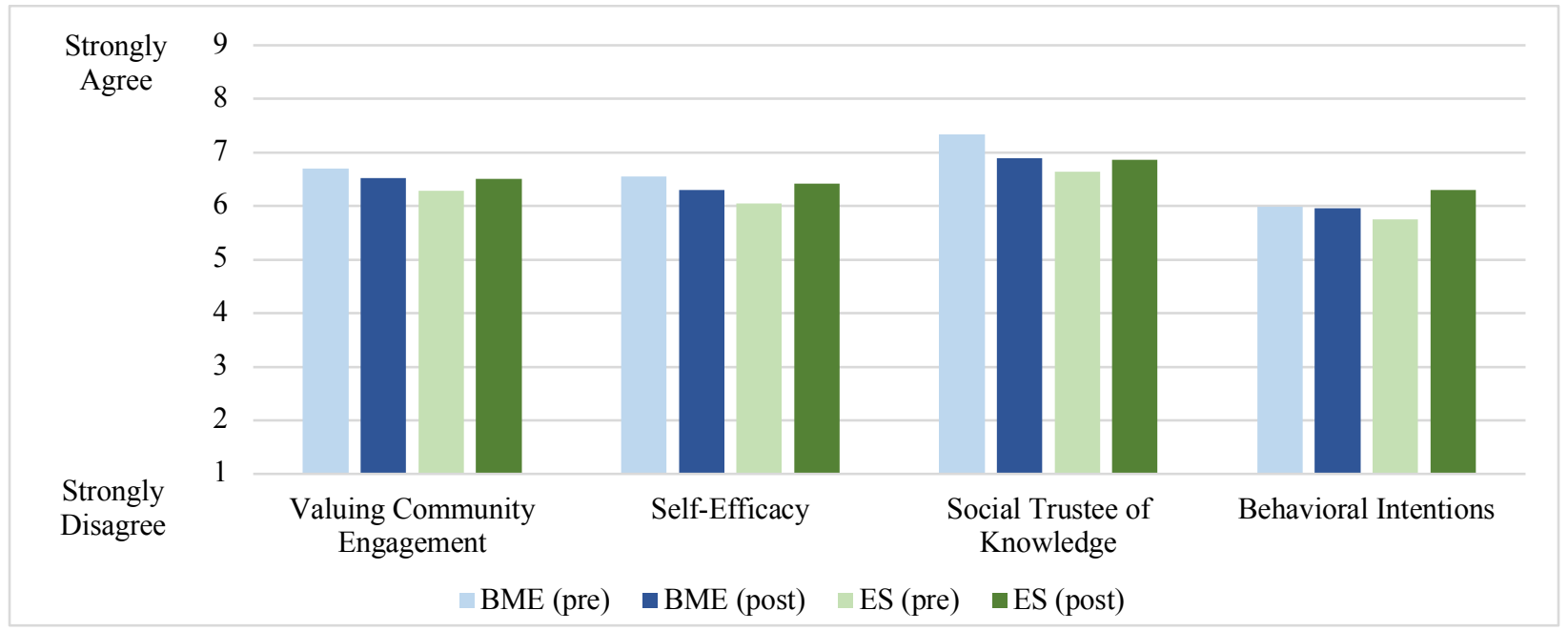

Figure 3. Pre/Post Responses to CMG Dispositions Sub-Domain 


\section{Descriptive Statistics}

\section{Civic-Minded Graduate Scale}

Figures 1, 2, and 3 present pre/post responses to each Subdomain of the Civic-Minded Graduate Scale by departmental course type where ES = Earth Science and BME = Biomedical Engineering. While changes showed variable trends, Biomedical Engineering students' responses tended to decrease whereas Earth Science student responses tended to increase.

For Biomedical Engineering students, the greatest change (in terms of magnitude) was to the construct, Social Trustee of Knowledge, where BME students' average responses decreased from pre $(M=7.34, S D=1.46)$ to post $(M=6.89, S D=1.65)$. BME students' average responses only increased on the Knowledge of Contemporary Social Issues construct from pre $(M=5.21, S D=$ $2.18)$ to post $(M=5.42, S D=2.10)$.

For Earth Science students, the greatest change (in terms of magnitude) was to the construct, Knowledge of Contemporary Social Issues, where Earth Science students' average responses increased from pre $(M=4.86, S D=1.81)$ to post $(M=5.82, S D=1.76)$. Earth Science students' average responses only decreased on the Listening construct from pre $(M=7.39, S D=1.28)$ to post $(M=7.32, S D=1.37)$.

While these trends suggest that the Earth Science curriculum was more effective in promoting students' civic-mindedness, it is important to note that the Earth Science students' pre-responses were below those of the Biomedical Engineering students for all but one CMG construct (Skills: Diversity). The pre-course difference was largest for the construct, Knowledge of Volunteer Opportunities. However, these trends were greatly reversed on the post-course responses, as the Earth Science students' post-course responses were greater than their Biomedical Engineering peers in six of the nine constructs.

\section{Interpersonal Tendencies}

In this section we report pre/post descriptive statistics by course type to four constructs: Interpersonal Self-Efficacy, Emotion Regulation, Perspective-Taking, and Empathic Concern. Figure 4 provides a graphical depiction of these results.

As with the CMG constructs, Biomedical Engineering students' responses decreased on each of these relational constructs. These changes were largest to the Perspective-Taking construct, with responses decreasing by .34 points from pre $(M=6.44, S D=1.40)$ to post $(M=6.10, S D=1.55)$. Conversely, Earth Science students' responses increased on each of the relational constructs. The largest changes were to the Emotion Regulation construct which increased by .33 points from pre $(M=5.50, S D=1.36)$ to post $(M=5.83, S D=1.19)$. 


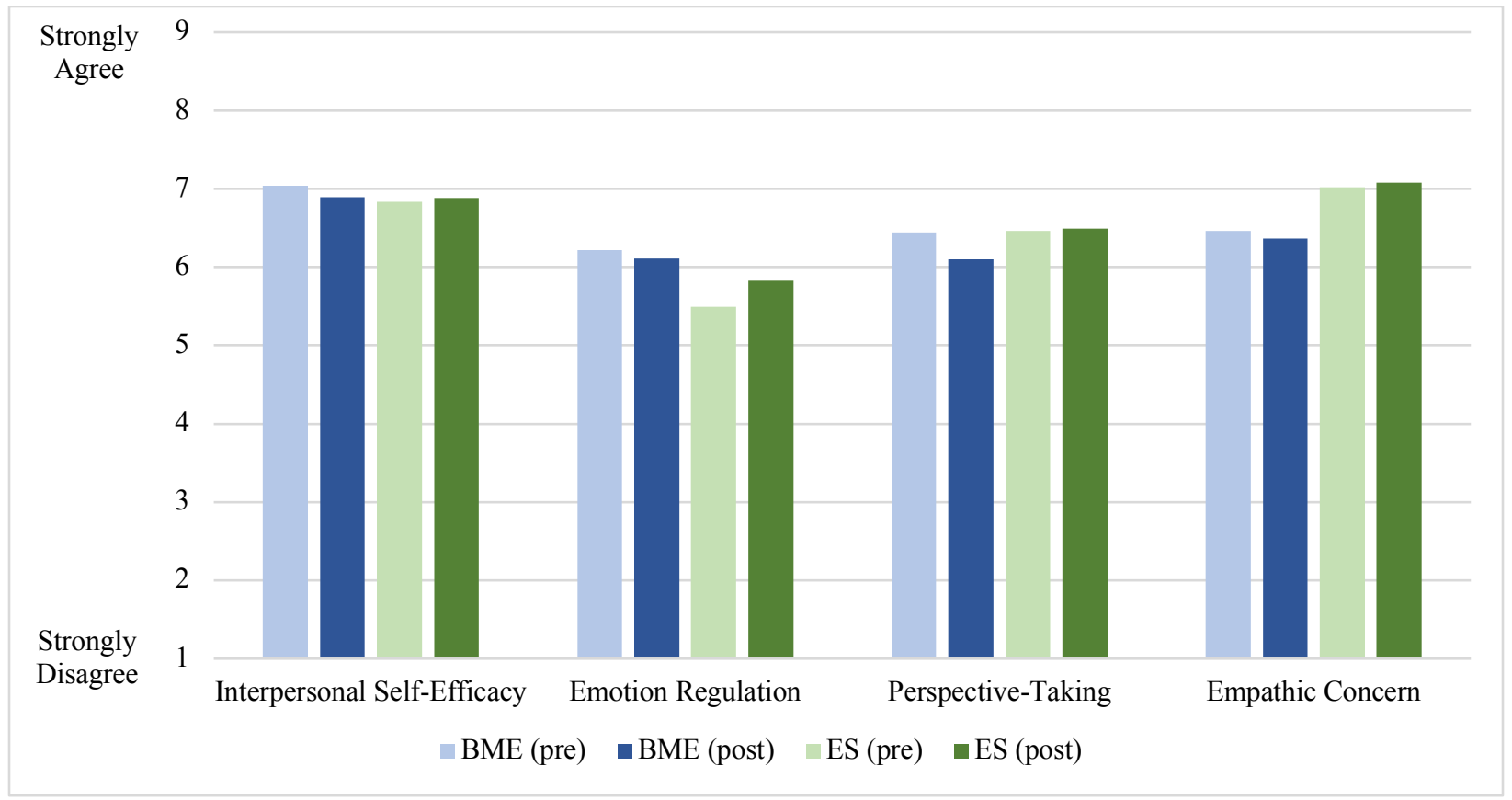

Figure 4. Pre/Post Responses to Relational Constructs by Departmental Course Type

\section{Moral Judgment (DIT2)}

Biomedical Engineering students' N2 scores decreased pre $(M=33.8, S D=14.5)$ to post $(M=$ $32.8, S D=16.4)$ whereas Earth Science students' N2 scores increased from pre $(M=30.3, S D=$ $14.9)$ to post $(M=34.4, S D=16.8)$. Hence, Earth Science students were slightly below those of their Biomedical Engineering peers pre-course but slightly higher post-course.

\section{Comparative Analyses (Pre/Post Wilcoxon Signed Rank Tests)}

A series of Wilcoxon Signed Rank Tests were conducted to ascertain if student changes were significant for any of the survey constructs. The effect size was computed by dividing the $\mathrm{z}$ value by the square root of the sample size. Table 2 summarizes all results. When ascertaining significance, we utilized a Bonferroni correction, where the threshold for significance was .05 divided by the number of tests conducted (15). Hence, tests were deemed significant if $p<.0033$.

Pre/post changes were compared by conducting a series of Wilcoxon Signed Rank Tests. These analyses revealed no significant changes on any of the survey constructs for Biomedical Engineering students. Earth Science student responses significantly increased on six constructs, including Knowledge of Volunteer Opportunities $(z=3.15, p<.0033, r=.32)$, Academic Knowledge and Technical Skills $(z=3.43, p<.0033, r=.34)$, Knowledge of Contemporary Social Issues $(z=5.09, p<.0033, r=.51)$, Behavioral Intentions $(z=3.87, p<.0033, r=.39)$, Emotion Regulation $(z=3.32, p<.0033, r=.33)$, and the DIT2 N2 Score $(z=3.26, p<.0033, r$ $=.33$ ). Using Cohen's [22] criterion, the effect size was large (i.e., $r>.50$ ) for Knowledge of Contemporary Social Issues and medium/moderate (i.e., $r>.30$ ) for all other listed constructs. 
Table 3. Wilcoxon Signed Rank Tests: Results by Course Type

\begin{tabular}{|c|c|c|c|c|c|c|c|c|c|c|c|c|c|}
\hline \multirow[t]{2}{*}{ Instrument } & \multirow[t]{2}{*}{ Construct } & \multicolumn{6}{|c|}{ Biomedical Engineering Course Enrollment } & \multicolumn{6}{|c|}{ Earth Science Course Enrollment } \\
\hline & & $\begin{array}{c}- \\
\text { Ranks } \\
\end{array}$ & $\begin{array}{c}+ \\
\text { Ranks } \\
\end{array}$ & Ties & $\mathrm{Z}$ & $\mathrm{p}$ & $\mathrm{r}$ & $\begin{array}{c}- \\
\text { Ranks } \\
\end{array}$ & $\begin{array}{c}+ \\
\text { Ranks } \\
\end{array}$ & Ties & $\mathrm{Z}$ & $\mathrm{p}$ & $\mathrm{r}$ \\
\hline \multirow[t]{10}{*}{$\begin{array}{l}\text { Civic-Minded } \\
\text { Graduate Scale }\end{array}$} & $\begin{array}{l}\text { Knowledge: Volunteer } \\
\text { Opportunities }\end{array}$ & 29 & 21 & 6 & -1.274 & 0.203 & 0.17 & 32 & 57 & 10 & -3.15 & $0.002 *$ & 0.32 \\
\hline & $\begin{array}{l}\text { Knowledge: Academic } \\
\text { Knowledge and } \\
\text { Technical Skills }\end{array}$ & 29 & 22 & 5 & -0.823 & 0.410 & 0.11 & 30 & 63 & 6 & -3.43 & $0.001 *$ & 0.34 \\
\hline & $\begin{array}{l}\text { Knowledge: } \\
\text { Contemporary Social } \\
\text { Issues }\end{array}$ & 24 & 26 & 6 & -0.871 & 0.384 & 0.12 & 27 & 65 & 7 & -5.087 & $0.000 *$ & 0.51 \\
\hline & Skills: Listening & 27 & 17 & 12 & -2 & 0.045 & 0.27 & 39 & 38 & 22 & -0.216 & 0.829 & 0.02 \\
\hline & Skills: Diversity & 27 & 18 & 11 & -0.975 & 0.330 & 0.13 & 42 & 51 & 6 & -0.888 & 0.375 & 0.09 \\
\hline & $\begin{array}{l}\text { Skills: Consensus- } \\
\text { Building }\end{array}$ & 23 & 26 & 7 & -0.249 & 0.803 & 0.03 & 36 & 52 & 11 & -1.884 & 0.060 & 0.19 \\
\hline & $\begin{array}{l}\text { Dispositions: Valuing } \\
\text { Community Engagement }\end{array}$ & 26 & 23 & 7 & -0.469 & 0.639 & 0.06 & 39 & 52 & 8 & -1.587 & 0.112 & 0.16 \\
\hline & $\begin{array}{l}\text { Dispositions: Self- } \\
\text { Efficacy }\end{array}$ & 28 & 22 & 6 & -1.336 & 0.182 & 0.18 & 37 & 51 & 11 & -2.731 & 0.006 & 0.27 \\
\hline & $\begin{array}{l}\text { Dispositions: Social } \\
\text { Trustee of Knowledge }\end{array}$ & 29 & 19 & 8 & -2.159 & 0.031 & 0.29 & 33 & 50 & 16 & -1.943 & 0.052 & 0.20 \\
\hline & Behavioral Intentions & 23 & 27 & 6 & -0.141 & 0.888 & 0.02 & 28 & 60 & 11 & -3.871 & $0.000^{*}$ & 0.39 \\
\hline \multirow{2}{*}{$\begin{array}{l}\text { Interpersonal } \\
\text { Reactivity Index }\end{array}$} & Perspective-Taking & 32 & 23 & 1 & -1.253 & 0.210 & 0.17 & 45 & 51 & 3 & -0.457 & 0.648 & 0.05 \\
\hline & Empathic Concern & 29 & 25 & 2 & -0.159 & 0.873 & 0.02 & 45 & 51 & 3 & -0.899 & 0.369 & 0.09 \\
\hline \multirow{2}{*}{$\begin{array}{l}\text { Relational } \\
\text { Constructs }\end{array}$} & Emotion Regulation & 34 & 22 & 0 & -0.644 & 0.519 & 0.09 & 30 & 65 & 4 & -3.324 & $0.001^{*}$ & 0.33 \\
\hline & $\begin{array}{l}\text { Interpersonal Self- } \\
\text { Efficacy }\end{array}$ & 30 & 24 & 2 & -0.564 & 0.573 & 0.08 & 40 & 53 & 5 & -0.814 & 0.416 & 0.08 \\
\hline $\begin{array}{l}\text { Defining Issues } \\
\text { Test } 2\end{array}$ & DIT2 N2 Score & 33 & 23 & 0 & -0.726 & 0.468 & 0.10 & 37 & 61 & 1 & -3.258 & $0.001 *$ & 0.33 \\
\hline
\end{tabular}

${ }^{*} p<.0033$ (two-tailed, with threshold based on Bonferroni correction); Biomedical Engineering $n=56 ;$ Earth Science $n=99$ 


\section{Triangulation with Observational Data}

We were surprised to find that, when comparing quantitative findings between Earth Science and Biomedical Engineering, disciplinary courses pertaining to the former showed evidence of several positive and moderate effects whereas the latter showed evidence of none. To explain this trend, we sought to triangulate observational data collected in select Earth Science and Biomedical Engineering courses. We conducted seven total observations of three Earth Science and two Biomedical Engineering courses. Each observation took place in a session that instructors deemed salient to ethics, even if ethics was not an explicit focus.

During observations of Earth Science courses, observers noted that students often engaged with moral and ethical principles, rules, and values. Even though this engagement was never explicitly discussed by instructors at length, there was always an ethical element implicit to the content being taught. More specifically, student engagement in what we might call implicit ethics instruction was accomplished through brief class discussion on a variety of topics, such as third world mining practices, fossil fuel consumption, and the economics of rare minerals.

While ethical issues, then, were often discussed in disciplinary courses, class discussions on the ethical import of these issues was, often, limited. By limited we mean that much of the ethical content of the issue was left implied, rather than thoroughly unpacked. For example, after a slide about exploitative mining practices on the African continent, one Earth Science instructor asked, rhetorically, if any of the students need the products that are made from these exploitatively mined rare minerals. One student briefly expressed their moral disgust, but there was no time given for students to reflect on these practices or to discuss varied perspectives.

In contrast, the Biomedical Engineering department's Senior Capstone course explicitly discussed ethics across three class sessions. After a brief overview of various ethical frameworks in the first session (i.e., virtue, principlism, deontology, utilitarianism), students later discussed a few ethical dilemmas related to academic and industry concerns. Ethics, here, was primarily cognitive, meaning students were encouraged to reason through a few cases that illustrated ethical dilemmas. In each observation, ethical principles, rules, and values were explicitly present. Yet, even when explicitly acknowledged, ethical principles and values remained abstract due to (or so we posit) a lack of applicability to students' own lived experiences. Importantly, while in some instances, authenticity was sought by the lead instructor, who connected examples to their prior industrial experiences, the students never "lived" the ethics that was discussed. Hence, the element of authenticity provided by incorporating practitioners' perspectives alone seems insufficient for promoting moral reasoning, civic-mindedness, and relational concerns, as evidenced by considering these qualitative patterns vis-à-vis the quantitative results.

This lack of engagement with authentic contexts where students can live ethics and reflect on these lived experiences, is another area in which the Earth Science and Biomedical Engineering departments differ. The Earth Science department has a history of prioritizing and highly valuing community-engagement in their undergraduate curriculum. At least six currently offered Earth Science courses require students to engage the community in some way. Hence, while ethics was seldom, if ever, explicitly unpacked by the Earth Science faculty, it seems that these experiences may have some influence in promoting student ethical development. 


\section{Limitations}

We would like to acknowledge one limitation of this study, and that is the reliance on self-report data coupled with limited qualitative data. While some instructional strategies may not appear to support deeper learning because of the relatively superficial coverage of content, causality is seldom clear to discern. While we hypothesize that student scores will improve from pre- to posttest in future modified courses, it is possible that students may be over-confident in their initial skill assessments. In other words, experiences in class (now, or in the future) may help students recalibrate their self-assessments to be more accurate. Therefore, some of the negative trends reported may be due to students becoming more attuned with their personal capacities and dispositions. There may also be test-retest effects that drive responses independent from a course alone. In the future, we will combine the quantitative analyses with more rigorous qualitative methods (e.g., observations, interviews) and we will triangulate findings to develop a more comprehensive account of causes underlying changes in student responses.

\section{Closing Discussion}

In this study, we reported and analyzed baseline data on students' ethical development for departmental courses offered in Earth Science and Biomedical Engineering. The survey analyses indicated that current Earth Science and Biomedical Engineering courses have wide-ranging impacts on students. Specifically, departmental instruction in the former showed moderate and positive impacts on students' civic-mindedness and ethical reasoning whereas the latter showed no impact. In comparing the findings between Earth Science and Biomedical Engineering courses, we posited that the experiential and community-engaged nature of several courses in the Earth Science curriculum may partly explain the positive trends.

This study serves to direct improvements in the formation of ethical cultures of STEM locally by describing how several discipline-based courses that lack an explicit focus influence students' professional formation. Coming into this study, we hypothesized that the current curriculum would generate little to no changes in the series of ethical constructs utilized herein. More specifically, prior to conducting this study, the authors' perceptions were that the two primary differences between the Earth Sciences and Biomedical Engineering curricula - beyond just discipline - is that Earth Science courses were lacking an explicit focus on ethics in the classroom and Biomedical Engineering courses were lacking any integration of communityengaged pedagogy. Hence, we would not have been altogether surprised to find positive trends among Biomedical Engineering students. However, despite the explicit integration of ethics, the findings from the Biomedical Engineering courses showed no impact on students' ethical development whereas the Earth Science courses showed several positive gains

While not a core focus of our analysis, Appendix B provides an overview of descriptive statistics for individual courses (course names are anonymized). In Earth Science, this course-level analysis indicates that individual courses, overall, tended to positively contribute to student growth in civic-mindedness, empathy, and related constructs. It may be that allowing students to engage with community members, even while not explicitly focusing on ethics, may have a greater impact on the ethical development of students than explicit discussion of ethics alone. 


\section{Future Work}

Future directions for this project include a Faulty Learning Community (FLC) wherein faculty will consider and discuss community engagement, scholarly values, ethical reflection, and curriculum transformation. As of this writing, faculty in each department are currently participating in this FLC, which is focused on integrating community-engaged learning and ethical reflection [13]. In the FLC, faculty have shared their strengths and wisdom in ethics and community engagement for collective discussion and reflection among their peers. Hence, expertise has come from not only the multidisciplinary team of investigators, but also from the disciplinary experts (the FLC members). In the future, our team's methods of research and organizational change will be further explored. We hope that these methods will, eventually, be transferrable to other contexts and allow the engineering education research community to evaluate the ethical formation of STEM students and faculty.

The following hypothesis will drive future phases of testing wherein baseline data will serve as the control: Students who participated in a redesigned course will show significantly higher levels of civic-mindedness, empathy, emotion regulation, interpersonal competence, and ethical reasoning post-course when compared to before course participation. In the future, we will also calculate Pearson correlations between students' post-course responses to the CMG, IRI, SSDS, and DIT2 to determine the inter-relations between these constructs. Lastly, we will utilize preliminary insights to develop and test a model of ethical becoming. These insights will be refined through the data integration step and will subsequently be tested by identifying research hypotheses and evaluating those hypotheses with specific quantitative methods.

\section{Acknowledgments}

This material is based upon work supported by the National Science Foundation under Grant No. 1737157. Any opinions, findings, and conclusions or recommendations expressed in this material are those of the author(s) and do not necessarily reflect the views of the National Science Foundation.

\section{References}

[1] ABET. (n.d., 01/18/19). Accreditation policy and procedure manual (APPM), 2019-2020. Available: https://www.abet.org/accreditation/accreditation-criteria/accreditation-policyand-procedure-manual-appm-2019-2020/

[2] E. A. Cech, "Culture of disengagement in engineering education?," Science, Technology, \& Human Values, vol. 39, no. 1, pp. 42-72, 2014.

[3] M. J. Drake, P. M. Griffin, R. Kirkman, and J. L. Swann, "Engineering ethical curricula: Assessment and comparison of two approaches," Journal of Engineering Education, vol. 94, no. 2, pp. 223-231, 2005.

[4] M. C. Loui, "Assessment of an engineering ethics video: Incident at Morales," Journal of Engineering Education, vol. 95, no. 1, pp. 85-91, 2006. 
[5] D. Bairaktarova and A. Woodcock, "Engineering ethics education: Aligning practice and outcomes," IEEE Communications Magazine, vol. 53, no. 11, pp. 18-22, 2015.

[6] H. E. Canary, J. R. Herkert, K. Ellison, and J. M. Wetmore, "Microethics and macroethics in graduate education for scientists and engineers: Developing and assessing instructional models," Paper presented at the American Society for Engineering Education, San Antonio, TX, 2012.

[7] D. R. Haws, "Ethics instruction in engineering education: A (mini) meta-analysis," Journal of Engineering Education, vol. 90, no. 2, pp. 223-229, 2001.

[8] J. L. Hess and G. A. Fore, "A systematic literature review of US engineering ethics interventions," Science and Engineering Ethics, vol. 24, no. 2, pp. 551-583, 2018.

[9] D. W. Orr, Earth in mind: On education, environment, and the human prospect. Washington, DC: First Island Press, 1994.

[10] C. D. Batson, "These things called empathy: Eight related but distinct phenomenon," in The Social Neuroscience of Empathy, J. Decety and W. Ickes, Eds. Cambridge, MA: MIT Press, 2009, pp. 3-15.

[11] K. S. Steinberg, J. A. Hatcher, and R. G. Bringle, "Civic-minded graduate: A north star," Michigan Journal of Community Service Learning, vol. 18, no. 1, pp. 19-34, 2011.

[12] J. R. Rest, D. Narvaez, S. J. Thoma, and M. J. Bebeau, "A neo-Kohlbergian approach to morality research," Journal of Moral Education, vol. 29, no. 4, pp. 381-395, 2000.

[13] G. A. Fore et al., "An introduction to the Integrated Community-Engaged Learning and Ethical Reflection Framework (I-CELER)," Paper presented at the American Society for Engineering Education, Salt Lake City, UT, 2018.

[14] J. R. Rest, D. Narvaez, S. J. Thoma, and M. J. Bebeau, "DIT2: Devising and testing a revised instrument of moral judgment," Journal of Educational Psychology, vol. 91, no. 4, pp. 644-659, 1999.

[15] M. H. Davis, "Measuring individual differences in empathy: Evidence for a multidimensional approach," Journal of Personality and Social Psychology, vol. 44, no. 1, pp. 113-126, 1983.

[16] M. L. Hoffman, Empathy and moral development: Implications for caring and justice. Cambridge, UK: Cambridge University Press, 2000.

[17] J. L. Hess, A. Chase, G. A. Fore, and B. Sorge, "Quantifying interpersonal tendencies of engineering and science students: A validation study," International Journal of Engineering Education, vol. 34, no. 6, 2018.

[18] S. J. Thoma, "Research on the Defining Issues Test," in Handbook of Moral Development, M. Killen and J. Smetana, Eds. Mahweh, NJ: Erlbaum, 2006.

[19] R. F. DeVellis, Scale development: Theory and applications. Los Angeles, CA: SAGE Publications, Inc., 2011.

[20] S. S. Shapiro and M. B. Wilk, "An analysis of variance test for normality (complete samples)," Biometrika, vol. 52, no. 3, pp. 591-611, 1965.

[21] F. Wilcoxon, "Individual comparisons by ranking methods," Biometrics Bulletin, vol. 1, no. 6, pp. 80-83, 1945.

[22] J. Cohen, "A power primer," Quantitative Methods in Psychology, vol. 112, no. 1, pp. 155-159, 1992. 


\section{Appendix A: Complete Survey}

\begin{tabular}{|c|c|c|}
\hline Category & Variable & Item Description \\
\hline \multirow[t]{30}{*}{ CMG } & KVO_01_pre & I know a lot about opportunities to become involved in the community. \\
\hline & KAK_01_pre & $\begin{array}{l}\text { I am able to plan or help implement an initiative that improves the } \\
\text { community. }\end{array}$ \\
\hline & SD_01_pre & $\begin{array}{l}\text { I appreciate how my community is enriched by having some cultural or ethnic } \\
\text { diversity. }\end{array}$ \\
\hline & KAK_02_pre & $\begin{array}{l}\text { I have the professional knowledge and skills that I need to help address } \\
\text { community issues. }\end{array}$ \\
\hline & BI_01_pre & I intend to stay current with the local and national news. \\
\hline & SCB_01_pre & I have often been able to persuade others to agree with my point of view. \\
\hline & KVO_02_pre & $\begin{array}{l}\text { I am very familiar with clubs and organizations that encourage and support } \\
\text { community involvement for college students. }\end{array}$ \\
\hline & SL_01_pre & I listen to others and understand their perspective on controversial issues. \\
\hline & DSE_09_pre & I can contribute to improving life in my community. \\
\hline & KAK_03_pre & $\begin{array}{l}\text { I feel confident that I will be able to apply what I have learned in my classes } \\
\text { to solve real problems in society. }\end{array}$ \\
\hline & DSTK_01_pre & I want to dedicate my career to improving society. \\
\hline & DVCE_01_pre & I like to be involved in addressing community issues. \\
\hline & KCSI_01_pre & I stay up to date on the current political issues in the community. \\
\hline & DVCE_02_pre & $\begin{array}{l}\text { I would say that the main purpose of work is to improve society through my } \\
\text { career. }\end{array}$ \\
\hline & KVO_03_pre & $\begin{array}{l}\text { I would say that most other students know less about community } \\
\text { organizations and volunteer opportunities than I do. }\end{array}$ \\
\hline & SL_02_pre & I am a good listener, even when peoples' opinions are different from mine. \\
\hline & BI_02_pre & I plan to participate in advocacy or political action groups after I graduate. \\
\hline & SD_02_pre & I am able to respond to others with empathy, regardless of their backgrounds. \\
\hline & BI_03_pre & I intend to be involved in volunteer service after I graduate. \\
\hline & DSTK_02_pre & $\begin{array}{l}\text { I feel a deep conviction in my career goals to achieve purposes that are } \\
\text { beyond my own self-interest. }\end{array}$ \\
\hline & KCSI_02_pre & $\begin{array}{l}\text { I am prepared to write a letter to the newspaper or community leaders about a } \\
\text { community issue. }\end{array}$ \\
\hline & KCSI_03_pre & I am aware of a number of community issues that need to be addressed. \\
\hline & DSE_02_pre & I am convinced that social problems are not too complex for me to help solve. \\
\hline & SCB_02_pre & $\begin{array}{l}\text { Other students who know me well would describe me as a person who can } \\
\text { discuss controversial social issues with civility and respect. }\end{array}$ \\
\hline & DSTK_03_pre & $\begin{array}{l}\text { I believe that I have a responsibility to use the knowledge that I have gained to } \\
\text { serve others. }\end{array}$ \\
\hline & DVCE_03_pre & $\begin{array}{l}\text { I have a sense of who I am, which includes a sincere desire to be of service to } \\
\text { others. }\end{array}$ \\
\hline & DSE_03_pre & I believe that having an impact on community problems is within my reach. \\
\hline & SCB_03_pre & $\begin{array}{l}\text { When members of my group disagree on how to solve a problem, I like to try } \\
\text { to build consensus. }\end{array}$ \\
\hline & SD_03_pre & $\begin{array}{l}\text { I prefer to work in settings in which I interact with people who are different } \\
\text { from me. }\end{array}$ \\
\hline & DVCE_04_pre & It is important for me to vote and be politically involved. \\
\hline
\end{tabular}




\begin{tabular}{|c|c|c|}
\hline \multirow[t]{14}{*}{ IRI } & EC_01_pre & I often have tender, concerned feelings for people less fortunate than me. \\
\hline & PT_01_pre & $\begin{array}{l}\text { I sometimes find it difficult to see things from the "other guy's" point of view. } \\
(-)\end{array}$ \\
\hline & EC_02_pre & $\begin{array}{l}\text { Sometimes I don't feel very sorry for other people when they are having } \\
\text { problems. (-) }\end{array}$ \\
\hline & PT_02_pre & I try to look at everybody's side of a disagreement before I make a decision. \\
\hline & EC_03_pre & $\begin{array}{l}\text { When I see someone being taken advantage of, I feel kind of protective } \\
\text { towards them. }\end{array}$ \\
\hline & PT_03_pre & $\begin{array}{l}\text { I sometimes try to understand my friends better by imagining how things look } \\
\text { from their perspective. }\end{array}$ \\
\hline & EC_04_pre & Other people's misfortunes do not usually disturb me a great deal. (-) \\
\hline & PT_04_pre & $\begin{array}{l}\text { If I'm sure I'm right about something, I don't waste much time listening to } \\
\text { other people's arguments. }(-)\end{array}$ \\
\hline & EC_05_pre & $\begin{array}{l}\text { When I see someone being treated unfairly, I sometimes don't feel very much } \\
\text { pity for them. (-) }\end{array}$ \\
\hline & EC_06_pre & I am often quite touched by things that I see happen. \\
\hline & PT_05_pre & $\begin{array}{l}\text { I believe that there are two sides to every question and try to look at them } \\
\text { both. }\end{array}$ \\
\hline & EC_07_pre & I would describe myself as a pretty soft-hearted person. \\
\hline & PT_06_pre & $\begin{array}{l}\text { When I'm upset at someone, I usually try to "put myself in his shoes" for a } \\
\text { while. }\end{array}$ \\
\hline & PT_07_pre & $\begin{array}{l}\text { Before criticizing somebody, I try to imagine how I would feel if I were in } \\
\text { their place. }\end{array}$ \\
\hline \multirow[t]{14}{*}{ SSDS } & IC_01_pre & $\begin{array}{l}\text { I feel prepared to work with people who define a problem differently than I } \\
\text { do. }\end{array}$ \\
\hline & ER_01_pre & When I cannot find the right solution to a problem, I tend to remain calm. \\
\hline & ER_02_pre & When dealing with complexity, I feel at-ease. \\
\hline & IC_02_pre & I consider another person's perspective before making a decision. \\
\hline & WP_01_pre & When I think about all of the individuals who need help, I go to pieces. (-) \\
\hline & ER_03_pre & I sometimes feel helpless when I am working on a very complex issue. (-) \\
\hline & IC_03_pre & I am prepared to meet and work with individuals from different backgrounds. \\
\hline & IC_04_pre & I value opinions that are different from my own. \\
\hline & ER_04_pre & I tend to lose control when I cannot find the right answer to a problem. (-) \\
\hline & WP_02_pre & Really, there is nothing I can do about the problems of the world. (-) \\
\hline & ER_05_pre & I don't shy away from complicated problems. \\
\hline & IC_05_pre & I am generally able to understand the viewpoints of others. \\
\hline & ER_06_pre & I tend to lose control when faced with several competing issues at once. (-) \\
\hline & IC_06_pre & Before finalizing a decision, I like to gather feedback from others. \\
\hline
\end{tabular}




\section{Appendix B: Student Construct Changes by Course Enrollment}

\section{Overall}

\begin{tabular}{|l|c|c|c|c|c|c|c|c|}
\hline \multirow{2}{*}{ Construct } & \multicolumn{3}{|c|}{ Biomedical Engineering } & \multicolumn{4}{c|}{ Earth Science } \\
\cline { 2 - 10 } & \multicolumn{2}{|c|}{ Pre } & \multicolumn{2}{|c|}{ Post } & \multicolumn{2}{c|}{ Pre } & \multicolumn{2}{c|}{ Post } \\
\cline { 2 - 9 } & $\mathrm{M}$ & SD & M & SD & M & SD & M & SD \\
\hline Volunteer Opportunities & 6.02 & 1.35 & 5.72 & 1.95 & 5.07 & 1.74 & 5.55 & 1.75 \\
\hline $\begin{array}{l}\text { Academic Knowledge and Technical } \\
\text { Skills }\end{array}$ & 6.45 & 1.63 & 6.24 & 1.71 & 5.66 & 1.47 & 6.14 & 1.52 \\
\hline Contemporary Social Issues & 5.21 & 2.18 & 5.42 & 2.10 & 4.86 & 1.81 & 5.82 & 1.76 \\
\hline Listening & 7.42 & 1.21 & 7.07 & 1.53 & 7.39 & 1.28 & 7.32 & 1.37 \\
\hline Diversity & 6.61 & 1.64 & 6.45 & 1.74 & 6.82 & 1.63 & 6.93 & 1.60 \\
\hline Consensus-Building & 6.47 & 1.30 & 6.44 & 1.45 & 6.23 & 1.51 & 6.53 & 1.44 \\
\hline Valuing Community Engagement & 6.71 & 1.60 & 6.52 & 1.67 & 6.29 & 1.72 & 6.51 & 1.69 \\
\hline Self-Efficacy & 6.55 & 1.49 & 6.30 & 1.36 & 6.05 & 1.49 & 6.42 & 1.56 \\
\hline Social Trustee of Knowledge & 7.34 & 1.46 & 6.89 & 1.65 & 6.63 & 1.88 & 6.86 & 1.77 \\
\hline Behavioral Intentions & 5.99 & 1.86 & 5.96 & 1.88 & 5.74 & 1.86 & 6.29 & 1.77 \\
\hline Perspective-Taking & 6.44 & 1.40 & 6.10 & 1.55 & 6.46 & 1.24 & 6.49 & 1.32 \\
\hline Empathic Concern & 6.47 & 1.46 & 6.37 & 1.68 & 7.02 & 1.56 & 7.08 & 1.53 \\
\hline Emotion Regulation & 6.21 & 1.28 & 6.11 & 1.47 & 5.50 & 1.36 & 5.83 & 1.19 \\
\hline Interpersonal Self-Efficacy & 7.04 & 1.18 & 6.91 & 1.40 & 6.83 & 1.32 & 6.88 & 1.34 \\
\hline DIT2 N2 Score & 33.75 & 14.46 & 32.78 & 16.35 & 30.28 & 14.88 & 34.40 & 16.79 \\
\hline
\end{tabular}

\section{By Individual Courses}

\section{Civic Minded Graduate Scale: Knowledge}

\begin{tabular}{|l|c|c|c|c|c|c|c|}
\hline & & \multicolumn{2}{|c|}{ Volunteer Opportunities } & \multicolumn{2}{c|}{ Academic Knowledge } & \multicolumn{2}{c|}{ Contemporary Social Issues } \\
\hline Course & n & Pre & Post & Pre & Post & Pre & Post \\
\hline BME2 & 15 & 6.3 & 6.1 & 6.6 & 6.6 & 4.9 & 5.2 \\
\hline BME3 & 23 & 5.9 & 5.9 & 6.4 & 6.2 & 5.6 & 5.7 \\
\hline BME4 & 19 & 5.9 & 5.1 & 6.4 & 5.9 & 5.1 & 5.3 \\
\hline GEO1 & 16 & 5.3 & 6.0 & 5.9 & 6.5 & 5.5 & 6.5 \\
\hline GEO2 & 13 & 5.3 & 5.5 & 5.3 & 5.9 & 4.3 & 5.2 \\
\hline GEO3 & 8 & 4.8 & 5.5 & 4.9 & 5.8 & 4.4 & 5.3 \\
\hline GEO4 & 16 & 4.6 & 4.9 & 4.9 & 5.4 & 4.4 & 5.0 \\
\hline GEO5 & 7 & 5.7 & 5.8 & 6.3 & 6.6 & 5.0 & 6.5 \\
\hline GEO6 & 7 & 3.8 & 4.0 & 5.8 & 5.7 & 4.0 & 4.5 \\
\hline GEO7 & 10 & 5.2 & 5.6 & 6.1 & 6.7 & 4.3 & 5.8 \\
\hline GEO8 & 17 & 4.9 & 5.7 & 5.8 & 6.4 & 5.5 & 6.6 \\
\hline GEO9 & 9 & 5.6 & 5.9 & 6.2 & 6.2 & 5.5 & 6.5 \\
\hline
\end{tabular}


Civic-Minded Graduate Scale: Skills

\begin{tabular}{|l|c|c|c|c|c|c|c|}
\hline & & \multicolumn{2}{|c|}{ Listening } & \multicolumn{2}{c|}{ Diversity } & \multicolumn{2}{c|}{ Consensus-Building } \\
\hline Course & n & Pre & Post & Pre & Post & Pre & Post \\
\hline BME2 & 15 & 7.3 & 7.2 & 6.8 & 6.6 & 6.1 & 6.2 \\
\hline BME3 & 23 & 7.7 & 7.1 & 6.4 & 6.5 & 6.6 & 6.3 \\
\hline BME4 & 19 & 7.2 & 6.8 & 6.8 & 6.2 & 6.7 & 6.6 \\
\hline GEO1 & 16 & 7.9 & 8.0 & 7.3 & 7.4 & 6.7 & 6.9 \\
\hline GEO2 & 13 & 7.5 & 6.6 & 6.3 & 6.6 & 5.5 & 5.9 \\
\hline GEO3 & 8 & 7.2 & 7.1 & 5.9 & 6.5 & 5.8 & 6.3 \\
\hline GEO4 & 16 & 7.1 & 7.2 & 6.9 & 6.3 & 5.9 & 5.8 \\
\hline GEO5 & 7 & 7.3 & 7.7 & 7.1 & 7.4 & 6.4 & 6.9 \\
\hline GEO6 & 7 & 6.9 & 7.3 & 6.8 & 6.2 & 6.5 & 6.1 \\
\hline GEO7 & 10 & 7.9 & 7.2 & 6.6 & 7.0 & 6.3 & 6.7 \\
\hline GEO8 & 17 & 7.4 & 7.5 & 7.2 & 7.4 & 6.3 & 7.0 \\
\hline GEO9 & 9 & 6.9 & 7.3 & 6.6 & 6.9 & 6.9 & 7.0 \\
\hline
\end{tabular}

Civic-Minded Graduate Scale: Dispositions and Behavioral Intentions

\begin{tabular}{|l|c|c|c|c|c|c|c|c|c|}
\hline & & \multicolumn{9}{|c|}{ Valuing Community Engagement } & \multicolumn{2}{|c|}{ Self-Efficacy } & \multicolumn{2}{c|}{$\begin{array}{l}\text { Social Trustee } \\
\text { of Knowledge }\end{array}$} & \multicolumn{2}{c|}{$\begin{array}{c}\text { Behavioral } \\
\text { Intentions }\end{array}$} \\
\hline Course & $\mathbf{n}$ & Pre & Post & Pre & Post & Pre & Post & Pre & Post \\
\hline BME2 & 15 & 7.0 & 7.0 & 6.4 & 6.2 & 7.6 & 7.3 & 6.0 & 5.8 \\
\hline BME3 & 23 & 6.6 & 6.6 & 6.4 & 6.6 & 7.1 & 6.7 & 6.2 & 6.6 \\
\hline BME4 & 19 & 6.7 & 5.9 & 7.0 & 6.0 & 7.5 & 6.7 & 5.8 & 5.2 \\
\hline GEO1 & 16 & 6.7 & 7.3 & 6.4 & 7.1 & 7.2 & 7.5 & 6.6 & 7.3 \\
\hline GEO2 & 13 & 6.0 & 6.2 & 6.5 & 6.1 & 6.5 & 6.6 & 5.2 & 5.9 \\
\hline GEO3 & 8 & 6.0 & 6.0 & 5.4 & 6.3 & 6.4 & 6.7 & 5.4 & 6.0 \\
\hline GEO4 & 16 & 5.7 & 5.4 & 5.6 & 5.9 & 5.9 & 5.8 & 5.2 & 5.3 \\
\hline GEO5 & 7 & 6.9 & 6.9 & 6.5 & 7.0 & 7.3 & 7.8 & 6.2 & 7.0 \\
\hline GEO6 & 7 & 6.1 & 5.6 & 5.6 & 5.5 & 6.7 & 6.9 & 4.8 & 5.0 \\
\hline GEO7 & 10 & 5.8 & 6.3 & 6.0 & 6.9 & 6.0 & 6.5 & 5.0 & 6.0 \\
\hline GEO8 & 17 & 6.9 & 7.3 & 6.1 & 6.5 & 7.3 & 7.4 & 6.8 & 7.0 \\
\hline GEO9 & 9 & 6.3 & 7.1 & 6.1 & 6.4 & 6.4 & 7.1 & 5.4 & 6.3 \\
\hline
\end{tabular}


Empathy and Interpersonal-Self-Efficacy

\begin{tabular}{|l|c|c|c|c|c|c|c|c|c|}
\hline & & \multicolumn{3}{|c|}{ Interpersonal Self-Efficacy } & \multicolumn{2}{c|}{ Emotion Regulation } & \multicolumn{2}{c|}{$\begin{array}{c}\text { Perspective- } \\
\text { Taking }\end{array}$} & \multicolumn{2}{c|}{$\begin{array}{c}\text { Empathic } \\
\text { Concern }\end{array}$} \\
\hline Course & $\mathrm{n}$ & Pre & Post & Pre & Post & Pre & Post & Pre & Post \\
\hline BME2 & 15 & 7.0 & 6.6 & 6.0 & 6.0 & 6.1 & 5.9 & 6.5 & 6.4 \\
\hline BME3 & 23 & 7.1 & 7.1 & 6.1 & 6.5 & 6.6 & 6.1 & 6.5 & 6.7 \\
\hline BME4 & 19 & 7.1 & 6.8 & 6.5 & 5.6 & 6.5 & 6.1 & 6.5 & 6.0 \\
\hline GEO1 & 16 & 7.2 & 7.4 & 5.7 & 6.0 & 6.8 & 6.9 & 7.6 & 7.8 \\
\hline GEO2 & 13 & 6.7 & 6.1 & 5.9 & 5.5 & 6.3 & 6.0 & 6.6 & 6.2 \\
\hline GEO3 & 8 & 6.4 & 6.9 & 5.9 & 6.1 & 6.6 & 6.5 & 6.7 & 6.5 \\
\hline GEO4 & 16 & 6.8 & 6.4 & 4.8 & 5.4 & 6.2 & 6.1 & 7.1 & 7.0 \\
\hline GEO5 & 7 & 6.9 & 7.3 & 5.4 & 6.3 & 6.8 & 6.5 & 7.6 & 7.8 \\
\hline GEO6 & 7 & 6.9 & 6.8 & 5.2 & 5.4 & 5.8 & 5.9 & 7.1 & 7.0 \\
\hline GEO7 & 10 & 6.4 & 6.9 & 5.6 & 6.0 & 6.3 & 6.6 & 6.2 & 6.7 \\
\hline GEO8 & 17 & 7.1 & 7.2 & 5.4 & 5.8 & 6.5 & 6.8 & 7.3 & 7.5 \\
\hline GEO9 & 9 & 6.9 & 7.0 & 5.8 & 6.1 & 6.7 & 6.5 & 6.9 & 7.0 \\
\hline
\end{tabular}

